\title{
Modeling the Performance of A Flow-Through Gas Diffusion Electrode for Electrochemical Reduction of $\mathrm{CO}$ or $\mathrm{CO}_{2}$
}

\author{
Yikai Chen, (1) Nathan S. Lewis, ${ }^{*, z}$ and Chengxiang Xiang ${ }^{z}$ \\ Beckman Institute and Division of Chemistry and Chemical Engineering, California Institute of Technology, Pasadena \\ California 91125, United States of America
}

\begin{abstract}
A flow-through gas diffusion electrode (GDE) consisting of agglomerate catalysts for $\mathrm{CO}$ or $\mathrm{CO}_{2}$ reduction, gas channels for reactants, aqueous electrolytes for ionic transport, and metallic current collectors was simulated and evaluated using a numerical model. The geometric partial current densities and Faradaic Efficiencies (FE) for $\mathrm{CH}_{4}, \mathrm{C}_{2} \mathrm{H}_{4}$ and $\mathrm{H}_{2}$ generation in GDEs were calculated and compared to the behavior of analogous aqueous-based planar electrodes. The pH-dependent kinetics for $\mathrm{CH}_{4}$ and $\mathrm{C}_{2} \mathrm{H}_{4}$ generation were used to represent the intrinsic catalytic characteristics for the agglomerate catalyst. The modeling indicated that relative to planar electrodes for either $\mathrm{CO}$ reduction $(\mathrm{COR})$ or $\mathrm{CO}_{2}$ reduction $\left(\mathrm{CO}_{2} \mathrm{R}\right)$, substantial increases in electrochemical reduction rates and Faradaic efficiencies are expected when flow-through GDEs are used. The spatially resolved $\mathrm{pH}$ and reaction rates within the flow-through GDEs were also simulated for two different operating pHs, and the resulting transport losses were analyzed quantitatively. For $\mathrm{CO}_{2}$ reduction, substantial loss of $\mathrm{CO}_{2}$ via chemical reaction with the locally alkaline electrolyte was observed due to the increased $\mathrm{pH}$ in operating GDEs.

( 2020 The Electrochemical Society ("ECS"). Published on behalf of ECS by IOP Publishing Limited. [DOI: 10.1149/1945-7111/ ab987a]
\end{abstract}

Manuscript submitted January 15, 2020; revised manuscript received May 26, 2020. Published July 1, 2020.

Supplementary material for this article is available online

Electrochemical $\mathrm{CO}_{2}$ or $\mathrm{CO}$ reduction is often performed in aqueous electrolytes, such as bicarbonate or carbonate solutions. The low solubility of $\mathrm{CO}_{2}$ and $\mathrm{CO}$ in aqueous solutions, in conjunction with the values of the liquid-phase diffusion coefficients of $\mathrm{CO}_{2}$ and $\mathrm{CO}$, consequently constrains the attainable current densities for $\mathrm{CO}_{2}$ or $\mathrm{CO}$ reduction. For example, at various nanostructured electrodes in aqueous solutions, the geometric current densities for $\mathrm{CO}$ reduction are limited to $<1 \mathrm{~mA} \mathrm{~cm}^{-2}$. ${ }^{1-4}$ The low mass-transportlimited current density in aqueous systems is consistent with Fick's law of diffusion, with a mass-transport-limited current density for $\mathrm{CO}$ reduction (COR) of $\sim 0.81 \mathrm{~mA} \mathrm{~cm}^{-2}$ at a boundary layer thickness of $\sim 100 \mu \mathrm{m}$.

One approach to increasing the operating current density of the electrode is to substantially reduce the thickness of the boundary layer. ${ }^{5}$ Gas-diffusion electrodes (GDEs) provide an opportunity to effectively reduce the boundary-layer thickness to hundreds of nanometers. Two general types of GDE configurations have been constructed and studied. In one configuration, no gas flow-through occurs at the GDE/electrolyte interface, and the pressure differential is regulated between the gaseous compartment and the liquid compartment. ${ }^{6-9}$ A similar flow-by pattern can also be achieved by the use of a membrane electrolyte that is directly bonded to GDEs, e.g., a membrane-electrode-assembly (MEA). ${ }^{10,11}$ Alternative configurations involve flow-through of gaseous reactants from the GDE/ electrolyte interface into the bulk liquid electrolytes. ${ }^{12-16}$ The flowby configurations have been modeled, simulated ${ }^{17,18}$ and are analogous physically to oxygen reduction electrodes in fuel cells, whereas the behavior of the flow-through configuration has not been evaluated or modeled quantitatively. The major focus of this study was to understand the local reaction rates and $\mathrm{pH}$ profiles for $\mathrm{COR}$ and to reveal challenges for $\mathrm{CO}_{2}$ utilization due to the highly alkaline local environments within GDEs. The concept of a gas/ vapor-fed cell for electrochemical reactions, such as $\mathrm{N}_{2}$ or $\mathrm{CO}_{2}$ fixation, and COR, has been considered extensively. Various configurations of GDEs have been designed and tested for $\mathrm{CO}_{2} \mathrm{R}$ or COR over a range of operating pHs and electrolytes. ${ }^{6-9,11,14,19-21}$ For example, highly active and stable Sn-based GDEs have been reported for selective formate generation, ${ }^{22}$ and $\mathrm{Cu}$-based GDEs have shown enhanced selectivity and activity for $\mathrm{CO}_{2} \mathrm{R}$ at abrupt junctions. ${ }^{6}$ Recently, Cu-nanoparticle-based GDEs in a flow-through configuration exhibited a partial current density of $50.8 \mathrm{~mA} \mathrm{~cm}^{-2}$ for $\mathrm{C}_{2} \mathrm{H}_{4}$ generation using $\mathrm{CO}$ as the feedstock. ${ }^{13}$ Herein the geometric partial current densities and Faradaic efficiencies (FEs) for COR and $\mathrm{CO}_{2} \mathrm{R}$ in a flow-through gas diffusion electrode (GDE) were simulated and compared to aqueous planar electrodes. Substantial increases in electrochemical reaction rates and Faradaic efficiencies were observed when such flow-through GDE's were used as compared to aqueous solutions, especially for COR. For $\mathrm{CO}_{2} \mathrm{R}$, the chemical reaction between $\mathrm{CO}_{2}$ and the locally alkaline electrolyte within GDEs contributed to substantial $\mathrm{CO}_{2}$ loss at high overpotentials.

\section{Modeling}

A catalyst-layer domain $(100 \mu \mathrm{m})$ and a bulk liquid-electrolyte domain $(100 \mu \mathrm{m})$ were modeled for the flow-through GDE (Fig. 1). The yellow region and the bubble are a proper illustration of the flow-through GDEs evaluated because in the experimental demonstration, ${ }^{23}$ the GDE was facing down and gaseous $\mathrm{CO}_{2}$ or $\mathrm{CO}$ was forced through the electrodes.

The bulk liquid-electrolyte layer was modeled as a stagnant liquid layer with a thickness of $100 \mu \mathrm{m}$, in which transport of electrolyte species was controlled by the diffusion and migration terms in the Nernst-Plank equation:

$$
\frac{\partial c_{i}}{\partial t}+\nabla \cdot\left(-D_{i} \nabla c_{i}-z_{i} u_{m, i} F c_{i} \nabla V\right)=R_{i},
$$

where $D_{i}, c_{i}, z_{i}$ and $u_{m, i}$ are the diffusion coefficient, concentration, charge number, and mobility, respectively, of species $i$ within the electrolyte, and $R_{i}$ is chemical/electrochemical reaction rate of the corresponding species. For an electrolyte at $\mathrm{pH}=14$, the only chemical reaction considered was water dissociation:

$$
\mathrm{H}_{2} \mathrm{O} \underset{k_{1 b}}{\stackrel{k_{1 f}}{\longrightarrow}} \mathrm{H}^{+}+\mathrm{OH}^{-} .
$$

For an electrolyte at $\mathrm{pH}=8$, three additional reactions were included in the model for the phosphate buffer solution: 


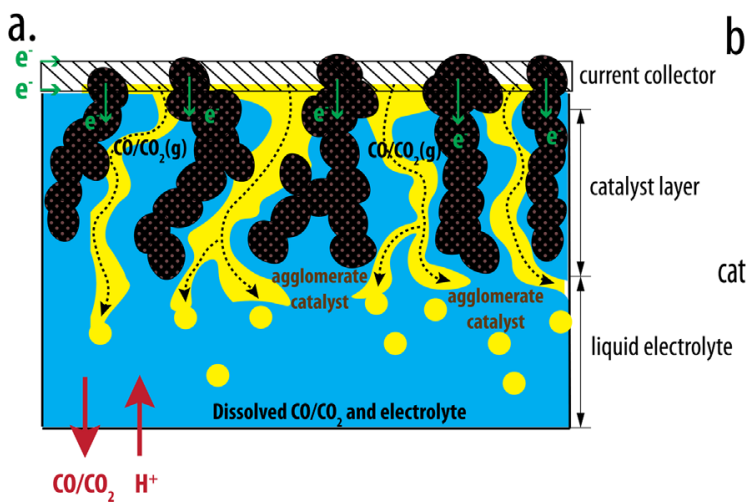

b.
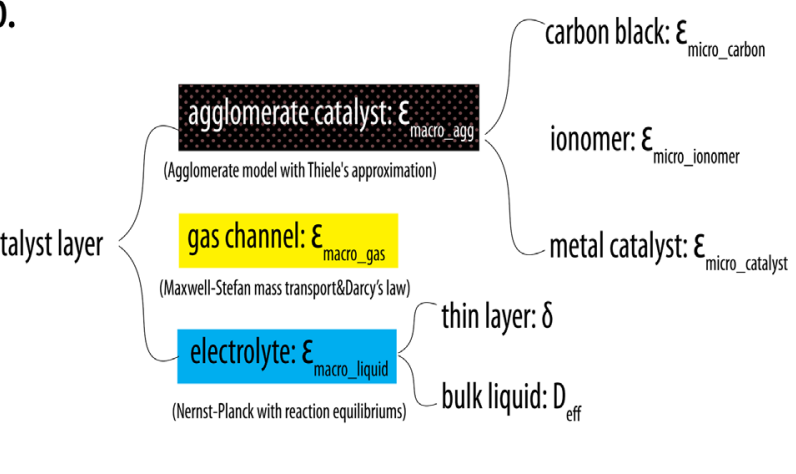

Figure 1. (a) A schematic illustration of a flow through gas diffusion electrode (GDE). (b) A schematic illustration of the catalyst layer containing an agglomerate catalyst, gas channel, and aqueous electrolyte.

$$
\begin{gathered}
\mathrm{H}_{3} \mathrm{PO}_{4} \underset{k_{2 b}}{\stackrel{k_{2 f}}{\longrightarrow}} \mathrm{H}_{2} \mathrm{PO}_{4}^{-}+\mathrm{H}^{+}, \\
\mathrm{H}_{2} \mathrm{PO}_{4}^{-} \underset{k_{3 b}}{\stackrel{k_{3 f}}{\rightleftarrows}} \mathrm{HPO}_{4}^{2-}+\mathrm{H}^{+}, \\
\mathrm{HPO}_{4}^{2-} \underset{k_{4 b}}{\stackrel{k_{4 f}}{\rightleftarrows}} \mathrm{PO}_{4}^{3-}+\mathrm{H}^{+} .
\end{gathered}
$$

In this Eq. 1, the second and third term on the left side represents diffusion and migration, respectively. These two terms, along with the electrochemical/chemical reaction $\left(R_{i}\right)$ affect the species transport throughout the GDE catalyst layer and the bulk liquid solution layer. We did not model the double layer structure at the electrode/ electrolyte interface in this study, consequently, no discontinuity is present in the electric potential throughput the modeling domain. The migration term was considered throughout the study. For example, different operating conditions ( $\mathrm{pH} 8$ vs $\mathrm{pH} 14$, COR vs $\mathrm{CO}_{2} \mathrm{R}$ ) were studied under different applied voltages and, when: (a) $\mathrm{H}^{+}$is non-negligible; (b) even when $\mathrm{H}^{+}$barely exists, $\mathrm{OH}^{-}$is non-negligible, along with other co-cations. The migration term was therefore always included in the simulation. The reaction rates of the buffer equilibrium, and the initial conditions for the aqueous electrolytes are summarized in Table SI (is available online at stacks.iop.org/JES/167/114503/mmedia). The continuity equation and mass conservation were assumed for all electrolyte species at the catalyst layer/bulk electrolyte interface. The dissolved $\mathrm{CO}$ concentration at the catalyst layer/bulk electrolyte interface was determined by the $\mathrm{CO}$ pressure at the interface. At the outer bulk electrolyte layer, constant concentrations of all electrolyte species at the initial conditions were assumed, due to the high convective fluxes beyond the stagnant liquid layer. The current collector was assumed to be an insulator for all electrolyte species.

The catalyst layer consisted of three components (Fig. 1b): the gas channel domain (gas phase), the electrolyte domain (liquid phase) and the agglomerate catalyst domain (mixed phase). In the gas channel domain, Darcy's law was used to describe the gas flow in the porous gas channel:

$$
q=-\frac{\kappa}{\mu} \nabla p
$$

where $q$ is the flux and $\kappa$ and $\mu$ are the intrinsic permeability and viscosity, respectively, of the medium. The quantity $\nabla p$ represents the pressure gradient along the gas channel. The inlet gas pressure in the GDE catalyst layer was set to $1 \mathrm{~atm}$. Before exiting into the bulk electrolyte domain, under operation, $\mathrm{CO}$ supplied through the gas channel can be electrochemically reduced at the agglomerate catalyst domain.

In the electrolyte domain within the catalyst layer, two types of liquid layers were modeled: a thin liquid layer with a thickness of $200 \mathrm{~nm}$ that surrounds the agglomerate, and a "bulk" liquid layer which was $10 \mathrm{vol} \%$ of the catalyst layer during steady-state operation. The liquid layer was responsible for the reactant transport to the agglomerate catalyst, while the "bulk" liquid electrolyte was responsible for the ionic transport to the bulk electrolyte during operation. At the thin liquid layer/gas channel interface, Henry's law was used to determine the concentration of dissolved $\mathrm{CO}$, the majority of which was supplied to the agglomerate catalysts:

$$
C=k P_{\text {gas }},
$$

where $C$ is the solubility of the gas at a fixed temperature (taken to be room temperature in this work) in a particular solvent, $k$ is the Henry's law constant and $P_{\text {gas }}$ is the partial pressure of the gas.

In the agglomerate catalyst domain, three microscopic components were modeled to describe the catalyst: the carbon black domain was used as the current collector to supply electrons into the GDE, the ionomer domain with a micro-porosity of 0.2 was used as the transport medium for dissolved $\mathrm{CO}$ and electrolyte species, and a metal catalyst was bonded to the carbon black as the active site for $\mathrm{CO}$ reduction. Effective diffusion coefficients were used in the agglomerate catalyst for $\mathrm{CO}$ and for all electrolyte species within the ionomer domain. The effects of $\mathrm{CO}$ dissolution and transport limitations in the porous catalyst agglomerates were approximated by an efficiency factor, $E$, using Thiele's modulus, $m L{ }^{24}$ For a firstorder irreversible reaction with a spherical interior surface in the agglomerate model, the efficiency factor was given by Ref. 25 :

$$
E=\frac{\frac{1}{\tanh (3 \mathrm{~mL})}-\frac{1}{3 \mathrm{~mL}}}{\mathrm{~mL}},
$$

in which

$$
\mathrm{mL}=L \sqrt{\frac{k}{C_{C O}^{0} D_{e f f}}} .
$$

Here, $L$ represented the characteristic length of the agglomerates, and for the sphere geometry was given by:

$$
L=\frac{R}{3}
$$

where $R$ is the radius of the agglomerate particle, $C_{C O}^{0}$ is the dissolved $\mathrm{CO}$ concentration at the gas channel and thin liquid-layer interface, and $D_{\text {eff }}$ is the effective CO diffusion coefficient within the ionomer domain. The reaction rate for a specific electrochemical 
reaction, $k$, was described as:

$$
k=\frac{A j_{g, O, C O R}}{n F} \exp \left(-\frac{\alpha_{O, C O R} F}{R T} \eta_{C O R}\right),
$$

where $A$ is the specific active surface area for the agglomerate model, which is defined as the total agglomerate particle surface area divided by the volume of the gas diffusion electrode. $F$ is Faraday's constant, $R$ is the universal gas constant, $T$ is the absolute temperature, $n$ is the number of electrons in each reaction, and $\eta_{C O R}$ is the overpotential of each reaction, which is the difference between an electrochemical reaction's thermodynamically determined reduction potential and the potential at which the redox process is observed experimentally. For COR, two reaction pathways, $\mathrm{CO}$ reduction to $\mathrm{CH}_{4}$ and $\mathrm{CO}$ reduction to $\mathrm{C}_{2} \mathrm{H}_{4}$, were considered within the catalyst layer. The $\mathrm{pH}$-dependent kinetics for both reactions were measured experimentally and fitted to a ButlerVolmer relation ${ }^{1}$.

$$
\begin{gathered}
j_{g}\left(\mathrm{C}_{2} \mathrm{H}_{4}\right)=J_{e} \exp \left[-\frac{\alpha_{e} F\left(E-E^{0}\right)}{R T}\right], \\
j_{g}\left(\mathrm{CH}_{4}\right)=J_{m}\left[\mathrm{H}^{+}\right] \exp \left[-\frac{\alpha_{m} F\left(E-E^{0}\right)}{R T}\right],
\end{gathered}
$$

where $j_{g}$ is the geometric current density in $\mathrm{mA} \mathrm{cm} \mathrm{cm}^{-2}$. The parameters $\alpha_{e}$ and $\alpha_{m}$ are the transfer coefficients for $\mathrm{C}_{2} \mathrm{H}_{4}$ and $\mathrm{CH}_{4}$ formation, respectively, and were estimated as 0.35 and 1.33 from Fig. 2(a). The constants $J_{e}$ and $J_{m}$ were $1.18 \times 10^{-8} \mathrm{~mA} \mathrm{~cm}^{-2}$ and $3.47 \times 10^{-18} \mathrm{~mA} \mathrm{~cm}^{-2}$, as calculated from the presented linear correlations.

When the attainable current densities were plotted versus the potential of the standard hydrogen electrode (SHE), the intrinsic kinetics assumed in the model for $\mathrm{CO}$ reduction to $\mathrm{CH}_{4}$ were $\mathrm{pH}$ dependent whereas the intrinsic kinetics vs SHE for $\mathrm{CO}$ reduction to $\mathrm{C}_{2} \mathrm{H}_{4}$ were independent of $\mathrm{pH}$. This behavior occurs because the rate-determining step for $\mathrm{CH}_{4}$ generation is a proton-coupled electron transfer reaction, whereas the rate-determining step for $\mathrm{C}_{2} \mathrm{H}_{4}$ is independent of the $\mathrm{pH}$ of the electrolyte. The volumetric current density of $\mathrm{COR}$ in the catalyst layer, $j_{C O R}$, was generated from the two electrochemical reductions listed above: $\mathrm{CO}$ to $\mathrm{C}_{2} \mathrm{H}_{4}$ and $\mathrm{CO}$ to $\mathrm{CH}_{4}$. The volumetric current density of each reaction was described as:

$$
j_{C O R}=n F\left(\frac{1}{\frac{\delta}{A C_{C O}^{0} D_{e f f}}+\frac{1}{k E}}\right) \text {, }
$$

where $\delta$ is the thickness of the thin liquid layer that surrounded the sphere and $A$ is the specific area. Two parallel paths for $\mathrm{CO} / \mathrm{CO}_{2}$ to diffuse to the active catalyst were assumed: a) diffusion through the thin liquid layer around the agglomerate particle, so that the thickness of the thin liquid layer is important; b) diffusion into the agglomerate particles, in which case the radius of the agglomerate sphere is important.

In addition to $\mathrm{CO}$ reduction, the hydrogen-evolution reaction (HER) also can occur within the catalyst layer domain. Previous experimental data (Fig. 2a) were used to model the partial volumetric current density generated due to the HER, and representative values of the exchange current density for the HER of $0.010 \mathrm{~mA} \mathrm{~cm}^{-2}$ and a transfer coefficient of 0.258 were taken from the literature. ${ }^{25}$ The data were fitted using the Butler-Volmer equation $^{25}$ :

$$
j_{g}(H E R)=j_{g, 0 \_H E R} \exp \left(-\frac{\alpha_{H E R} F}{R T} \eta_{H E R}\right),
$$

where $j_{g, 0 \_H E R}$ is the exchange-current density for HER, $\alpha_{H E R}$ is the transfer coefficient, and $\eta_{H E R}$ represents the overpotential for this electrochemical reaction. The corresponding volumetric current density, $j_{H E R}$, was then obtained by multiplication with the specific active surface area for the agglomerate model.

Potential was applied to drive the electrochemical reaction within the GDE catalyst layer, but no extra electric potential was applied to influence migration in the device. The equilibrium potential represents an interplay between the partial volumetric current densities that determine the rest potential when several electrochemical processes are proceeding simultaneously. The thermodynamic potentials for the reduction of $\mathrm{CO}$ to $\mathrm{C}_{2} \mathrm{H}_{4}$ and $\mathrm{CH}_{4}$ are $-0.34 \mathrm{~V}$ and $-0.25 \mathrm{~V}$, correspondingly, vs $\mathrm{NHE}$ at $\mathrm{pH} 7$, and the equilibrium potential of the HER is $0 \mathrm{~V}$ vs RHE. When a specific potential is applied, these three electrochemical reactions proceed simultaneously but have different overpotentials due to their different thermodynamic potentials.

The total volumetric current density generated from electrochemical reactions in the catalyst layer was expressed as:

$$
j_{\text {total }}=j_{\mathrm{CO} \rightarrow \mathrm{CH}_{4}}+j_{\mathrm{CO} \rightarrow \mathrm{C}_{2} \mathrm{H}_{4}}+j_{\mathrm{HER}} .
$$

This total volumetric current density contributes to the electrochemical reaction rate for $\mathrm{OH}^{-}$within the ionomer domain in the catalyst layer:

$$
\begin{gathered}
R_{\mathrm{OH}^{-} \text {_electrochem }}=j_{\text {total }} / F, \\
R_{\mathrm{OH}^{-}}=R_{\mathrm{OH}^{-} \text {_electrochem }}+R_{\mathrm{OH}^{-} \text {_chem }} .
\end{gathered}
$$

For other species in the ionomer domain, the $R_{i \_ \text {electrochem }}$ term is absent, thus:

$$
R_{i}=R_{i-c h e m} .
$$

When $\mathrm{CO}_{2}$ is used as the supply gas instead of $\mathrm{CO}$, a $\mathrm{CO}_{2}$ acid/base equilibrium in aqueous electrolytes is also present. In this work, initial conditions were set to $1 \mathrm{M} \mathrm{HCO}_{3}^{-}$and therefore the initial $\mathrm{pH}$ was 7.8. The $\mathrm{CO}_{2}$ concentration at equilibrium was calculated as $33.6 \mathrm{mM}$ based on Henry's law. Other than water dissociation, the following chemical reactions were also considered ${ }^{26}$ :

$$
\begin{gathered}
\mathrm{CO}_{2}+\mathrm{H}_{2} \mathrm{O} \underset{k_{5 b}}{\stackrel{k_{5 f}}{\rightleftarrows}} \mathrm{H}^{+}+\mathrm{HCO}_{3}^{-}, \\
\mathrm{CO}_{2}+\mathrm{OH}^{-} \underset{k_{6 b}}{\stackrel{k_{6 f}}{\rightleftarrows}} \mathrm{HCO}_{3}^{-}, \\
\mathrm{HCO}_{3}^{-} \underset{k_{7 b}}{\stackrel{k_{7 f}}{\rightleftarrows}} \mathrm{H}^{+}+\mathrm{CO}_{3}^{2-}, \\
\mathrm{HCO}_{3}^{-}+\mathrm{OH}^{-} \underset{k_{8 b}}{\stackrel{k_{8 f}}{\rightleftarrows}} \mathrm{H}_{2} \mathrm{O}+\mathrm{CO} .
\end{gathered}
$$

The $\mathrm{CO}_{2}$ to $\mathrm{CO}$ reaction is not the rate-limiting step in $\mathrm{CO}_{2}$ reduction reactions, ${ }^{27-30}$ consistently, almost identical reduction products have been observed experimentally for $\mathrm{CO}_{2}$ reduction and $\mathrm{CO}$ reduction. ${ }^{31}$ Due to the lack of systematic experimental data for $\mathrm{CO}_{2}$ reduction kinetics at various local $\mathrm{pH}$ values at the electrode surface, the kinetic parameters for $\mathrm{CO}_{2}$ reduction were obtained by 
a.

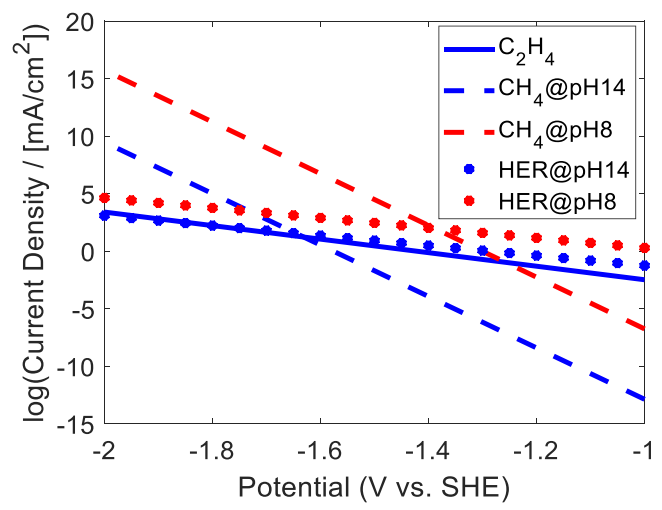

C.

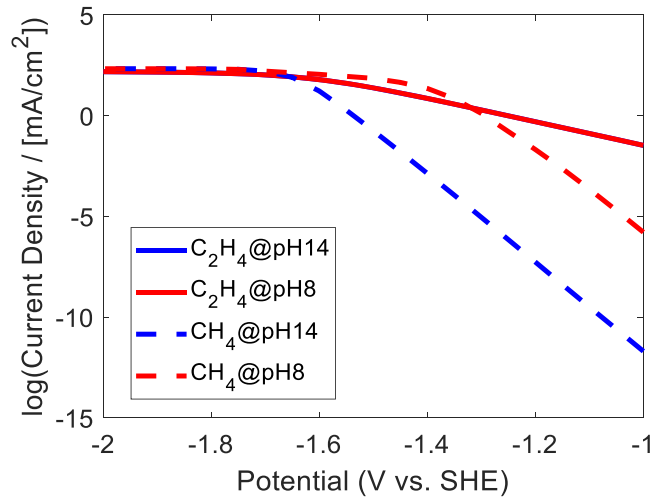

b.

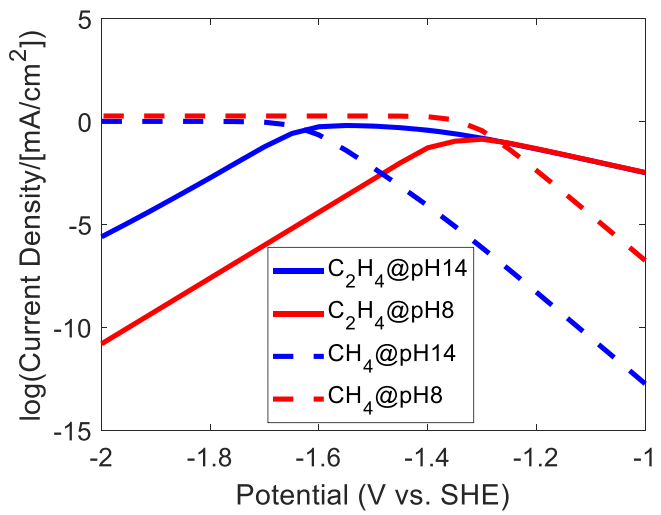

d.

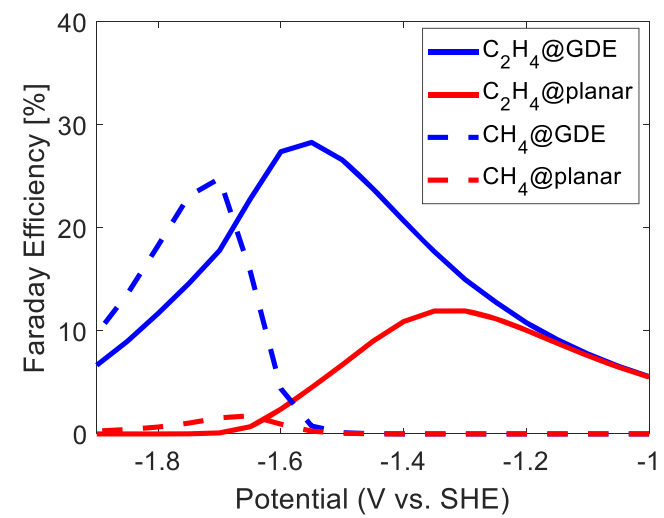

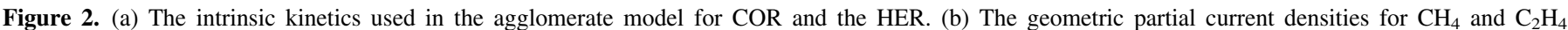

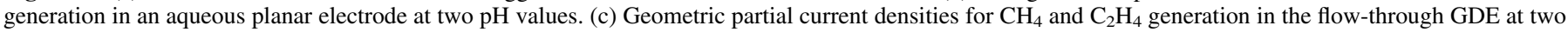
pHs. (d) Faradaic efficiencies for $\mathrm{CH}_{4}$ and $\mathrm{C}_{2} \mathrm{H}_{4}$ generation using an aqueous planar electrode or a flow-through GDE.

replacing the concentration of $\mathrm{CO}$ with $\mathrm{CO}_{2}$. For $\mathrm{CO}_{2}$ reduction, the simulation did not take into account the generation of formate as an intermediate, in accordance with observations for many $\mathrm{Cu}$ based catalysts. ${ }^{27-29}$ The chemical reaction rates for $\mathrm{CO}_{2}$ within the highly alkaline GDE structures should be independent of the product branching ratios for $\mathrm{CO}_{2}$ reduction and should only be affected by the total operating current density, which determines the rate of hydroxide generation in the GDE.

The standard FEM solver in the COMSOL multi-physics package was used to obtain the modeled electrochemical behavior. The maximum element size and the maximum element growth rate for this 1-D model were $10 \mathrm{~nm}$ and 1.4 , respectively. A relative tolerance of the corresponding variable of 0.001 was applied as the convergence criterion for all simulations.

\section{Results and Discussion}

Figure 2a shows the intrinsic kinetics used in the model at two different $\mathrm{pHs}$ for COR and the HER, for both the planar electrode and the GDE. As described by Eqs. 8 and 9, the partial current density for $\mathrm{C}_{2} \mathrm{H}_{4}$ generation was independent of the operating $\mathrm{pH}$, while the partial current density for $\mathrm{CH}_{4}$ generation shifted by $\sim 360 \mathrm{mV}$ vs SHE, according to the Nernst equation. Figure $2 \mathrm{~b}$ shows the simulated partial current densities for $\mathrm{CH}_{4}$ generation and $\mathrm{C}_{2} \mathrm{H}_{4}$ generation as a function of the applied potential at a planar electrode in an aqueous electrolyte with moderate stirring, with the hydrodynamic boundary layer at the planar electrode set to $100 \mu \mathrm{m}$. The limiting current density for COR was $1 \mathrm{~mA} \mathrm{~cm}^{-2}$ for an initial $\mathrm{pH}$ value of 14 and was $1.9 \mathrm{~mA} \mathrm{~cm}^{-2}$ for an initial $\mathrm{pH}$ of 8 . At high overpotentials, the partial current density associated with COR to
$\mathrm{C}_{2} \mathrm{H}_{4}$ was nearly zero at both $\mathrm{pH}$ values, due to the competing reactions for $\mathrm{CH}_{4}$ generation and limited $\mathrm{CO}$ supply from the bulk solution. An aqueous based, nanostructured electrode, illustrated in Fig. S1, was also modeled and simulated, and very similar limiting current density values for COR were observed relative to planar electrodes. The low limiting current density for COR at aqueous planar and nanostructured electrodes is consistent with many previous observations, in which the partial current density for COR is limited to $\sim 1 \mathrm{~mA} \mathrm{~cm}^{-2}{ }^{1-4}$ The $\mathrm{pH}$ dependent kinetics for $\mathrm{COR}$ and the local $\mathrm{CO}$ concentration for the catalytic reaction were responsible for the different product branching ratios at large negative potentials. For example, the highly alkaline local environment for the nanostructured electrode (Fig. S2b) relative to the planar electrode substantially reduced the rate of $\mathrm{CH}_{4}$ generation as the electrode potential became more negative. As a result, in the nanostructured electrodes the partial current density for $\mathrm{CH}_{4}$ generation was on the same order of magnitude as the partial current density for $\mathrm{C}_{2} \mathrm{H}_{4}$ generation (Fig. S2a). In contrast, in the flowthrough GDE configuration (Fig. 2c), the limiting partial current densities for $\mathrm{C}_{2} \mathrm{H}_{4}$ generation and $\mathrm{CH}_{4}$ generation were $158 \mathrm{~mA} \mathrm{~cm}^{-2}$ and $212 \mathrm{~mA} \mathrm{~cm}^{-2}$, respectively, in electrolytes with two different $\mathrm{pHs}$. The high electrochemically active surface area (ECSA) and the small effective boundary layer thickness within the catalyst layer were responsible for the substantial increase in the attainable current densities for COR relative to a planar electrode. Furthermore, Figs. $2 \mathrm{~b}$ and $2 \mathrm{c}$ indicate that beyond $-1.8 \mathrm{~V}$ vs SHE the partial current density for the planar electrode for $\mathrm{CO}$ reduction reached a plateau, and the plateau current density was $\sim 1 \mathrm{~mA} \mathrm{~cm}^{-2}$. In contrast, for the GDE configuration, the partial current density associated with COR reached the same value at $-1.25 \mathrm{~V}$ vs SHE. 
For the planar electrode, this partial current density is dominated by $\mathrm{CH}_{4}$ generation, but for the GDE configuration the partial current density is dominated by $\mathrm{C}_{2} \mathrm{H}_{4}$ generation.

Figure 2d shows the Faradaic efficiencies for the planar electrode and the flow-through GDE, respectively, in the $\mathrm{pH}=14$ electrolyte. In the flow-through GDE configuration, the Faradaic efficiency for $\mathrm{C}_{2} \mathrm{H}_{4}$ generation exhibited a maximum of $28.3 \%$ at an electrode potential of $-1.55 \mathrm{~V}$ vs SHE, whereas the maximum Faradaic efficiency for $\mathrm{CH}_{4}$ was $24.8 \%$ at $-1.7 \mathrm{~V}$ vs SHE. With a planar electrode under the same initial conditions, the maximum Faradaic efficiencies for $\mathrm{C}_{2} \mathrm{H}_{4}$ and $\mathrm{CH}_{4}$ were $11.9 \%$ at $-1.3 \mathrm{~V}$ vs SHE and $1.8 \%$ at $-1.65 \mathrm{~V}$ vs SHE, respectively. In both the GDE and planar electrode configurations, the maximum Faradaic efficiencies for methane and ethylene occurred at mutually different overpotentials. The maximum FEs for COR occurred at more positive potentials for the planar electrode configuration than for the GDE configuration. At large negative potentials $(<-1.6 \mathrm{~V}$ vs SHE), the current densities at the planar electrode approached the masstransport-limited current densities for $\mathrm{COR}$ and consequently a large enhancement of the FEs for $\mathrm{C}_{2} \mathrm{H}_{4}$ generation (from $1.8 \%$ to $24.8 \%$ ) were observed in the flow-through GDE configurations relative to the planar configurations. In general, with the GDE configuration, the Faradaic efficiencies for production of both ethylene and methane were larger than on than the planar electrode, attesting to the strong dependence of the Faradaic efficiency on mass transport.

A low CO coverage within the catalyst layer has been assumed previously. To model the HER performance under high CO coverage, the transfer coefficient was decreased to $10 \%$ of its original $(0.01)$ value. The $\mathrm{CO}$ coverage had little effect on the partial current densities (Fig. S3(a)). For either low or high coverages of $\mathrm{CO}$, the maximum Faradaic efficiencies for methane and ethylene production occurred at mutually different overpotentials. With an electrolyte having an initial $\mathrm{pH}$ of 14 , the difference in overpotential for maximum Faradaic efficiency between methane and ethylene became larger (by $19.2 \%$ ) as the assumed CO coverage increased. Figure S3(b) shows that the Faradaic efficiency had a strong dependence on the $\mathrm{CO}$ gas coverage. At high $\mathrm{CO}$ coverage, the maximal methane and ethylene Faradaic efficiencies were $\sim 50 \%$ and $\sim 75 \%$, respectively, but the Faradaic efficiencies were $<30 \%$ for low CO coverage.

The spatially resolved $\mathrm{pH}$ profiles and volumetric generation rates for COR were modeled and simulated at two different $\mathrm{pHs}$ under moderate overpotential $(-1.65 \mathrm{~V}$ vs SHE) and the assumption of a high $\mathrm{CO}$ coverage. In the flow-through $\mathrm{GDE}$ at $\mathrm{pH}=8$, due to the high operating current density of the GDE, a large $\mathrm{pH}$ differential of 4.5 was observed within the bulk electrolyte layer relative to the planar electrode (Fig. 3a). Within the catalyst layer in the flowthrough GDE, the $\mathrm{pH}$ increased by 1.8 , from 12.5 to 14.3 . Although the GDE nominally operated under near-neutral $\mathrm{pH}$ conditions (bulk $\mathrm{pH}=8$ ), during operation and under moderate overpotentials, the local $\mathrm{pH}$ within the catalyst layer was highly alkaline, even with $1.0 \mathrm{M}$ buffer in the electrolyte. When the initial $\mathrm{pH}$ was set to 14 , the $\mathrm{pH}$ increased by 0.9 in the flow-through GDE configuration, compared to 0.01 in the planar electrode. Figure $3 \mathrm{~b}$ indicates that the volumetric generation rate of $\mathrm{C}_{2} \mathrm{H}_{4}$ along the catalyst layer in the flow-through GDE configuration was independent of $\mathrm{pH}$ and was also not dependent on location in the catalyst layer, due to the intrinsic kinetics (Eq. (8)). In contrast, the volumetric generation rate of $\mathrm{CH}_{4}$ was substantially lower as the distance towards the current collector decreased, where the local $\mathrm{pH}$ was high and the solution was locally highly alkaline. Moreover, the volumetric generation rate of $\mathrm{CH}_{4}$ also increased when the initial $\mathrm{pH}$ of the electrolyte was set to $\mathrm{pH}=8$.

In addition to using phosphate buffer, bicarbonate was also used to produce an electrolyte with an initial $\mathrm{pH}=8$. The partial current density for $\mathrm{C}_{2} \mathrm{H}_{4}$ generation was independent of the operating $\mathrm{pH}$, and thus did not depend on the buffer species. Under low to moderate overpotentials, due to the higher buffer strength, the partial current density for $\mathrm{CH}_{4}$ generation was higher with phosphate buffer than with bicarbonate buffer (Fig. S4). In contrast, at high overpotentials, the GDEs reached the same plateau of current density, $212 \mathrm{~mA} \mathrm{~cm}^{-2}$, in either buffered electrolyte because the current density was primarily determined by diffusion of $\mathrm{CO}(\mathrm{g})$ to the spherical surface.

In the flow-through GDE configuration, the limiting current density for $\mathrm{COR}$, with an initial $\mathrm{pH}$ value of 14 , reached $370 \mathrm{~mA} \mathrm{~cm}^{-2}, 737 \mathrm{~mA} \mathrm{~cm}^{-2}$ and $1460 \mathrm{~mA} \mathrm{~cm}^{-2}$ with an effective boundary layer thickness of $200 \mathrm{~nm}, 100 \mathrm{~nm}$ and $50 \mathrm{~nm}$, respectively (Fig. 4a). Decreasing the boundary layer thickness resulted in an increased $\mathrm{CO}$ reduction current density because the effective diffusion length of $\mathrm{CO}$ was reduced accordingly. At high overpotentials, the limiting partial current density was inversely proportional to the thickness of the boundary layer, because in those cases, $\mathrm{CO}$ diffusion was the dominant factor in the rate of $\mathrm{CO}$ reduction. As shown in Fig. $4 \mathrm{~b}$, decreasing the agglomerate radius had a similar effect on the $\mathrm{CO}$ reduction rate as decreasing the effective boundary layer thickness.

Low $\mathrm{CO}_{2}$ utilization efficiencies have been observed for aqueous-based electrochemical $\mathrm{CO}_{2}$ reduction, due to bicarbonate crossover in cells that utilize ion-selective membranes. ${ }^{32}$ The flowthrough GDE configuration presents additional constraints that impede effective utilization of $\mathrm{CO}_{2}$. Figure 5a shows the spatially resolved $\mathrm{pH}$ profile for $\mathrm{CO}_{2} \mathrm{R}$ at three different potentials in $1 \mathrm{M}$ bicarbonate electrolyte at $\mathrm{pH}=7.8$. At the electrode/electrolyte interface, the $\mathrm{pH}$ values increased to 8.06, 11.92 and 13.52, corresponding to the different applied potentials, whereas at the current collector site, the $\mathrm{pH}$ values further increased to 8.6, 12.63 and 14.13, respectively. As shown in Fig. S5, at $-1.65 \mathrm{~V}$ vs SHE, the volumetric generation rate of $\mathrm{C}_{2} \mathrm{H}_{4}$ was independent of position and remained at $37 \mathrm{~mol} \mathrm{~m}^{-3} \mathrm{~s}^{-1}$ within the GDE, due to the lack of a.

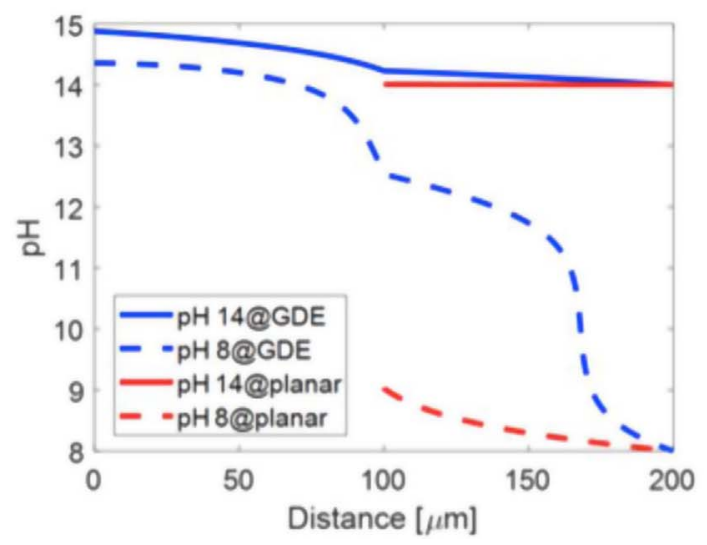

b.

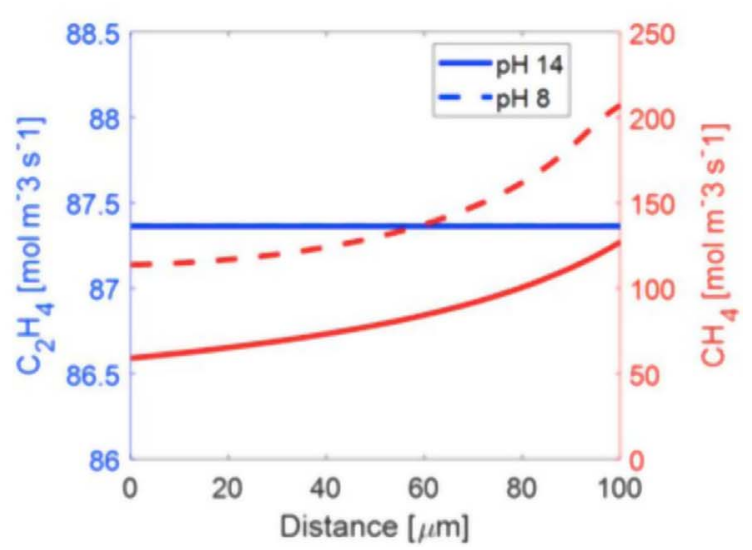

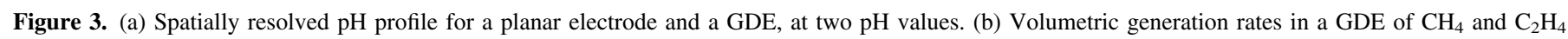
during $\mathrm{COR}$ at two $\mathrm{pH}$ values. 
a.

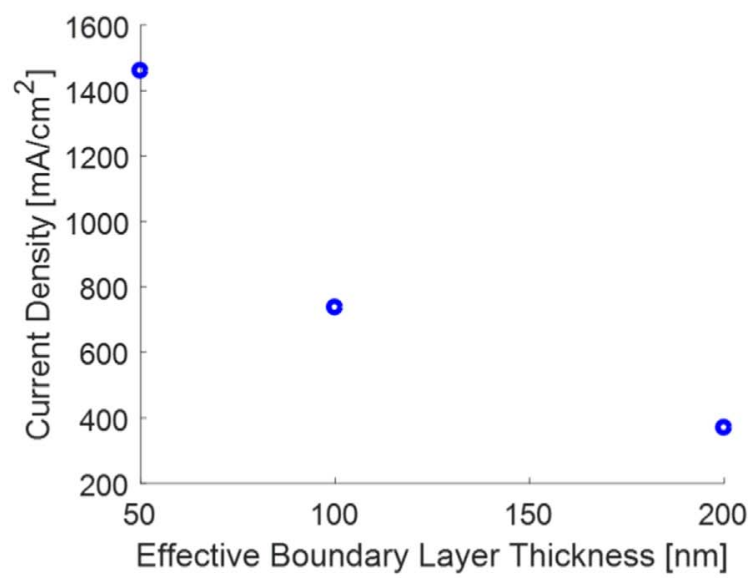

b.

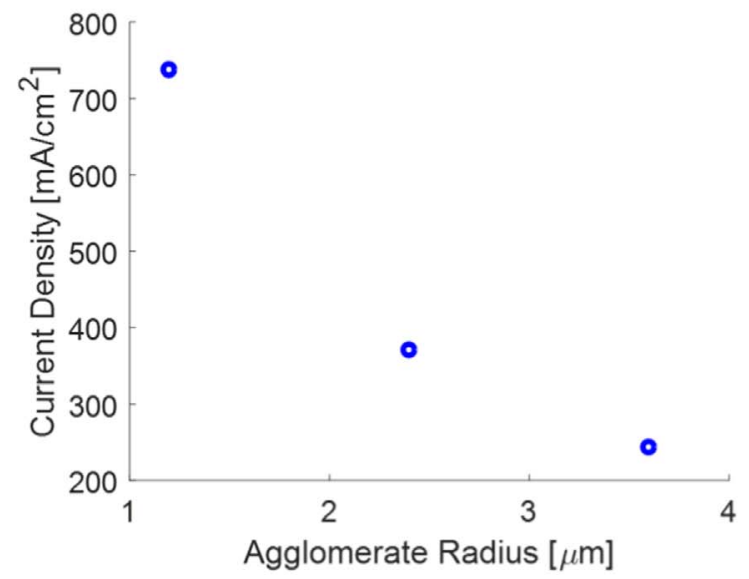

Figure 4. Current density for CO reduction as a function of different (a) effective boundary layer thicknesses and (b) agglomerate radii.

a.

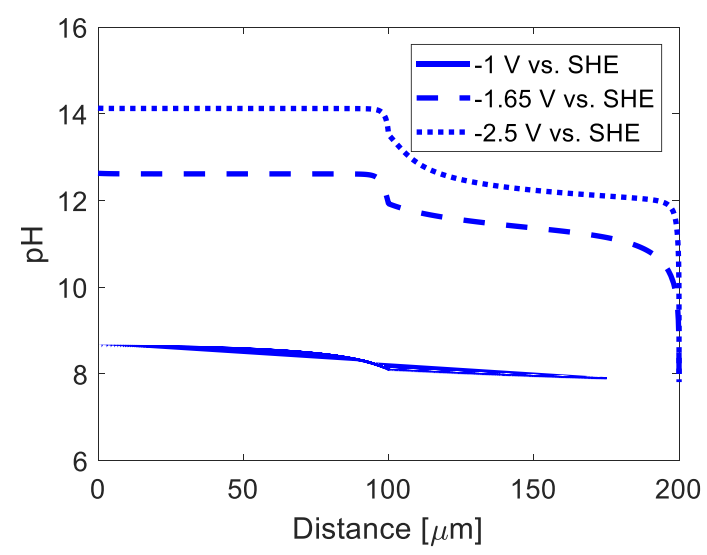

b.

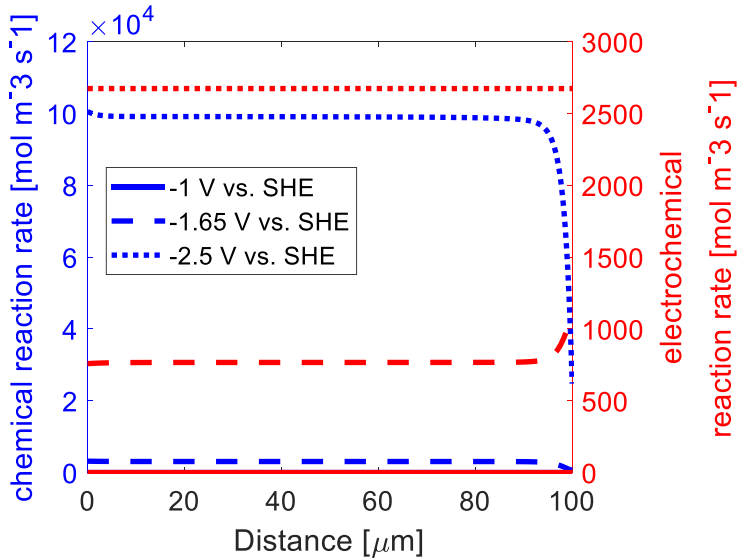

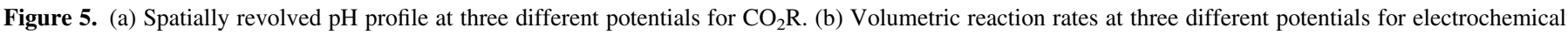
$\mathrm{CO}_{2} \mathrm{R}$ and for chemical reaction with alkaline electrolytes.

dependence of the rate on the local $\mathrm{pH}$. In contrast, the volumetric generation rate of $\mathrm{CH}_{4}$ increased from $697 \mathrm{~mol} \mathrm{~m}^{-3} \mathrm{~s}^{-1}$ to $1047 \mathrm{~mol} \mathrm{~m}^{-3} \mathrm{~s}^{-1}$ as the local $\mathrm{pH}$ at the electrode/electrolyte interface decreased from 12.6 to 11.9 .

The highly alkaline conditions at the catalyst layer caused locally substantial $\mathrm{CO}_{2}$ consumption due to the acid/base equilibrium within the GDE. Figure $5 \mathrm{~b}$ shows the chemical and electrochemical volumetric $\mathrm{CO}_{2}$ consumption rates at three different overpotentials. At a potential of $-1.65 \mathrm{~V}$ vs $\mathrm{SHE}$, the chemical $\mathrm{CO}_{2}$ consumption rate increased from to $631 \mathrm{~mol} \mathrm{~m}^{-3} \mathrm{~s}^{-1}$ at the electrode/electrolyte interface to $3156 \mathrm{~mol} \mathrm{~m}^{-3} \mathrm{~s}^{-1}$ at the current collector site, whereas the electrochemical rate decreased from $1079 \mathrm{~mol} \mathrm{~m}^{-3} \mathrm{~s}^{-1}$ to $758 \mathrm{~mol} \mathrm{~m}^{-3} \mathrm{~s}^{-1}$. When the applied potential was $-2.5 \mathrm{~V}$ vs SHE, the chemical volumetric $\mathrm{CO}_{2}$ consumption rates along the catalyst layer were at least an order of magnitude higher than the corresponding electrochemical rates. At very low overpotentials ( $-1 \mathrm{~V}$ vs SHE) that resulted in the $\mathrm{pH}$ within the flow-through GDEs being close to the bulk $\mathrm{pH}$ due to the low operating current density, the chemical consumption of $\mathrm{CO}_{2}$ was negligible. In contrast, at large overpotentials, substantial $\mathrm{CO}_{2}$ loss within the flow-through GDEs was observed due to the chemical consumption of $\mathrm{CO}_{2}$ in the highly alkaline environment.

For a flow-through configuration, the gas supply was assumed to be sufficient to maintain a stable $\sim 1 \mathrm{~atm}$ gas pressure within the catalyst layer. When the gas supply is not large enough, the extreme case, i.e., the nanostructured electrode configuration, was simulated. At $-1.4 \mathrm{~V}$ vs SHE, the partial current density for $\mathrm{CO}_{2}$ reduction was $9.11 \mathrm{~mA} \mathrm{~cm}^{-2}$ for sufficient $\mathrm{CO}_{2}$ gas supply; $8.41 \mathrm{~mA} \mathrm{~cm}{ }^{-2}$ for a fixed gas supply of $1 \mathrm{~mol} \mathrm{~cm} \mathrm{~cm}^{-2} \mathrm{~s}^{-1}$; and $7.36 \mathrm{~mA} \mathrm{~cm}^{-2}$ for the nanostructured electrode configuration. Thus sufficient gas supply, moderate gas supply, and no gas supply cases, respectively, have been evaluated for an electrode potential of $-1.4 \mathrm{~V}$ vs SHE. The resulting difference in terms of partial current density for $\mathrm{CO}_{2}$ reduction due to the different types of gas supply has been evaluated. The generation of gaseous products $\left(\mathrm{CH}_{4}, \mathrm{C}_{2} \mathrm{H}_{4}\right.$ or $\mathrm{H}_{2}$ ) was assumed to have minimal effects on transport within the GDEs. The $\mathrm{CO}_{2}$ concentration distribution was simulated for all of these cases (Fig. S6). The total current density generated at $-1.65 \mathrm{~V}$ vs SHE from $\mathrm{CO}_{2} \mathrm{R}$ under $1 \mathrm{~atm}$ in the catalyst layer from the flow-through GDE was $>5000 \mathrm{~mA} \mathrm{~cm}^{-2}$, whereas for a planar electrode configuration, the limiting current density for $\mathrm{CO}_{2} \mathrm{R}$ was $<20 \mathrm{~mA} \mathrm{~cm}^{-2}$.

The performance of GDEs was also dependent on the water content and water displacement within the structure. As the water content in the GDE layer changed from $10 \%$ to $5 \%$, the $\mathrm{C}_{2} \mathrm{H}_{4}$ generation rate remained the same as previously analyzed due to its lack of dependence on the local $\mathrm{pH}$, but the $\mathrm{CH}_{4}$ generation rate decreased substantially. In contrast, the partial current density associated with the HER increased substantially. For example, at $-1.4 \mathrm{~V}$ vs SHE, the partial current density of $\mathrm{CH}_{4}$ generation was $14.5 \mathrm{~mA} \mathrm{~cm}^{-2}$ with $10 \%$ water content, and decreased to $1.52 \mathrm{~mA} \mathrm{~cm}^{-2}$ with $5 \%$ water content, whereas the partial current density associated with the HER increased from $4.2 \mathrm{~mA} \mathrm{~cm}^{-2}$ to $177 \mathrm{~mA} \mathrm{~cm}^{-2}$.

At this specific potential, Fig. S7 shows the local $\mathrm{OH}^{-}$ concentration within the GDE under these assumptions of two 
different amounts of water content. As the water content decreased, the $\mathrm{OH}^{-}$transferred with a smaller diffusion coefficient, which resulted in a higher $\mathrm{OH}^{-}$concentration with the catalyst layer and eventually led to a lower partial current density for $\mathrm{CH}_{4}$ generation and a higher partial current density related to the HER.

\section{Conclusions}

Flow-through GDEs provide an effective approach to increase the limiting current density for $\mathrm{COR}$ or $\mathrm{CO}_{2} \mathrm{R}$ relative to planar or nanostructured electrodes, with the internal structure within the GDE playing an important role in the electrochemical behavior. Limiting partial current densities for both $\mathrm{C}_{2} \mathrm{H}_{4}$ and $\mathrm{CH}_{4}$ generation were essentially constant as the initial electrolyte conditions were varied. Substantial increases in Faradaic efficiencies for $\mathrm{COR}$ or $\mathrm{CO}_{2} \mathrm{R}$ are also expected in the flow-through GDEs relative to traditional planar electrodes, especially at large overpotentials. The local $\mathrm{CO}$ or $\mathrm{CO}_{2}$ concentration, the local $\mathrm{pH}$ at the reaction site, the $\mathrm{pH}$-dependent kinetics of the catalysts, and the detailed agglomerate catalyst morphology all played important roles in determining the volumetric reaction rates for COR or $\mathrm{CO}_{2} \mathrm{R}$. For $\mathrm{CO}_{2} \mathrm{R}$ at relatively large overpotentials, the $\mathrm{pH}$ within the flow-through GDEs is highly alkaline even with buffered electrolytes, with the highly alkaline local $\mathrm{pH}$ contributing to substantial $\mathrm{CO}_{2}$ loss due to the acid/base equilibrium within the GDE.

\section{Acknowledgments}

This material is based on work performed by the Joint Center for Artificial Photosynthesis, a DOE Energy Innovation Hub, supported through the Office of Science of the U.S. Department of Energy under Award Number DE-SC0004993.

\section{ORCID}

Yikai Chen (iD https://orcid.org/0000-0002-2955-9671

\section{References}

1. Y. Hori, R. Takahashi, Y. Yoshinami, and A. Murata, J. Phys. Chem. B, 101, 7075 (1997).

2. X. F. Feng, K. L. Jiang, S. S. Fan, and M. W. Kanan, ACS Central Sci, 2, 169 (2016).
3. C. W. Li, J. Ciston, and M. W. Kanan, Nature, 508, 504 (2014).

4. A. Verdaguer-Casadevall, C. W. Li, T. P. Johansson, S. B. Scott, J. T. McKeown, M. Kumar, I. E. L. Stephens, M. W. Kanan, and I. Chorkendorff, J. Am. Chem. Soc., 137, 9808 (2015).

5. A. J. Bard and L. R. Faulkner, Electrochemical Methods: Fundamentals and Applications (Wiley, New York) 2nd ed. (2000).

6. C. T. Dinh et al., Science, 360, 783 (2018).

7. M. Jouny, W. Luc, and F. Jiao, Nat. Catal., 1, 748 (2018).

8. S. C. Ma, M. Sadakiyo, R. Luo, M. Heima, M. Yamauchi, and P. J. A. Kenis, J. Power Sources, 301, 219 (2016).

9. T. T. H. Hoang, S. Verma, S. C. Ma, T. T. Fister, J. Timoshenko, A. I. Frenkel, P. J. A. Kenis, and A. A. Gewirth, J. Am. Chem. Soc., 140, 5791 (2018).

10. G. K. S. Prakash, F. A. Viva, and G. A. Olah, J. Power Sources, 223, 68 (2013)

11. D. S. Ripatti, T. R. Veltman, and M. W. Kanan, Joule, 3, 240 (2019).

12. R. L. Cook, R. C. Macduff, and A. F. Sammells, J. Electrochem. Soc., 137, 607 (1990).

13. L. H. Han, W. Zhou, and C. X. Xiang, ACS Energy Lett., 3, 855 (2018).

14. T. T. Zhuang et al., Nat. Catal., 1, 421 (2018).

15. K. Ogura, R. Oohara, and Y. Kudo, J. Electrochem. Soc., 152, D213 (2005).

16. H. Yano, F. Shirai, M. Nakayama, and K. Ogura, J. Electroanal. Chem., 519, 93 (2002).

17. L. C. Weng, A. T. Bell, and A. Z. Weber, Phys. Chem. Chem. Phys., 20, 16973 (2018).

18. L. C. Weng, A. T. Bell, and A. Z. Weber, Energ Environ Sci, 12, 1950 (2019).

19. B. Kim, F. Hillman, M. Ariyoshi, S. Fujikawa, and P. J. A. Kenis, J. Power Sources, 312, 192 (2016).

20. D. T. Whipple, E. C. Finke, and P. J. A. Kenis, Electrochem Solid St, 13, D109 (2010).

21. P. De Luna, R. Quintero-Bermudez, C. T. Dinh, M. B. Ross, O. S. Bushuyev, P. Todorovic, T. Regier, S. O. Kelley, P. D. Yang, and E. H. Sargent, Nat. Catal., 1, 103 (2018).

22. D. Kopljar, A. Inan, P. Vindayer, N. Wagner, and E. Klemm, J. Appl. Electrochem. 44, 1107 (2014).

23. L. Han, W. Zhou, and C. Xiang, ACS Energy Lett., 3, 855 (2018).

24. E. W. Thiele, Ind. Eng. Chem., 31, 916 (1939).

25. L. J. J. Janssen, Journal of Applied Electrochemistry , 17, 1177 (1987).

26. J. R. Rumble, CRC Handbook of Chemistry and Physics (CRC Press, Boca Raton) 100th ed. (2019).

27. C. G. Vayenas et al. (ed.), Modern Aspects of Electrochemistry (Springer, New York) 89 (2008).

28. S. Nitopi et al., Chem. Rev., 119, 7610 (2019).

29. K. Kuhl, E. Cave, D. Abram, and T. Jaramillo, Energy \& Environmental Science, $\mathbf{5}$ 7050 (2012).

30. R. Kortlever, J. Shen, K. J. P. Schouten, F. Calle-Vallejo, and M. T. M. Koper, The Journal of Physical Chemistry Letters, 6, 4073 (2015).

31. L. Wang et al., ACS Catal., 8, 7445 (2018).

32. K. P. Kuhl, E. R. Cave, D. N. Abram, and T. F. Jaramillo, Energ Environ Sci, 5 , 7050 (2012). 